Marsili R, Rossi G. Mechanical components dynamic characterization using thermoelastic stress analysis and digital image correlation.

\title{
MECHANICAL COMPONENTS DYNAMIC CHARACTERIZATION USING THERMOELASTIC STRESS ANALYSIS AND DIGITAL IMAGE CORRELATION
}

\author{
Roberto MARSILI ${ }^{1}$, Gianluca ROSSI ${ }^{2}$ \\ Università degli Studi di Perugia, Dipartimento di Ingegneria \\ Via Duranti, 1 - 06125 Perugia, Italy \\ 'e-mail: roberto.marsili@unipg.it; ${ }^{2}$ e-mail: gianluca.rossi@unipg.it
}

\begin{abstract}
In this work the possibility to characterize mechanical components combining thermoelastic measurement technique (TSA) and digital image correlation (DIC) is studied. The combination of these two different methodologies allows to analyze thermo-mechanical characteristics of materials such as plastic and rubber, which are difficult to study with the only thermoelastic methodology. The digital image correlation allows to determinate the first invariant of deformation $\varepsilon 1$, using a differential thermocamera. Lack of adiabatic conditions, essential for methodology use, makes analysis not simple. Digital image correlation allows to obtain the same information by correlating digital images acquired during static or dynamic deformationof an object, but with limitations linked to acquisition system. An accurate analysis is dedicated to the study of first invariant of deformation related to Young's module variation, performed by load cycles with variable amplitude and displacement. Comparative analysis between the two measurement methodologies has been performed on rubber samples loaded by dynamic compression.
\end{abstract}

Keywords: Thermoelasticity; Digital Image Correlation; Speckle; Rubber; TSA; DIC

\section{INTRODUCTION}

Thermoelasticity measurement principle is based on thermoelastic effect, described by Lord Kelvin in 1853 [1] that introduced the fundamental thermoelastic law under the hypothesis of adiabatic transformation. This law correlates the temperature variation of a homogeneous, isotropic, linear elastic material with his first stress invariant $\Delta(\sigma 1+\sigma 2+\sigma 3)$.

$$
\Delta \mathrm{T}=\frac{\mathrm{T} \cdot \alpha \cdot \Delta\left(\sigma_{1}+\sigma_{2}+\sigma_{3}\right)}{\mathrm{c}_{\mathrm{p}} \cdot \rho}
$$

where:

$\alpha$ : thermal expansion coefficient;

$\mathrm{T}$ : absolute temperature of the component;

$\rho$ : density;

$\mathrm{c}_{\mathrm{p}}$ : thermal capacity at constant pressure;

$\sigma_{1}+\sigma_{2}+\sigma_{3}$ : components of the tension tensor.

The fundamental equation that relates the variation of temperature within a homogeneous, isotropic, linear elastic material with stress state is:

$$
d \mathrm{~T}=\frac{\mathrm{T}}{\mathrm{c}_{\mathrm{p}} \cdot \rho} \cdot \frac{\partial \sigma_{i j}}{\partial T} \cdot d \varepsilon_{i j}+\frac{\delta q}{c_{v}}
$$

where:

$\delta q$ : heat generated or absorbed inside the control volume;

$\mathrm{c}_{\mathrm{v}}$ : thermal capacity at constant volume;

$\sigma_{i, j}:$ stress tensor;

$\varepsilon_{i, j}:$ strain tensor;

For isotropic materials in its linear elastic field the Lamé constant $\gamma$ can be expressed as:

$$
\gamma=\frac{\alpha \cdot \mathrm{E}}{(1-2 v)}
$$

where:

E : Young module;

v: Poisson module;

The Lamé constant $\gamma$ and thermal expansion coefficient $\alpha$ can be considered, in a first approximation, independent of temperature, then:

$$
\frac{\partial \sigma_{i j}}{\partial T}=-\gamma \cdot \delta_{i j}=-\frac{E}{1-2 v} \cdot \alpha \cdot \delta_{i j}
$$

Assuming $\mathrm{T}_{0}$ as the temperature on the initial state and substituting the expression (4) in the equation (2) can be easily obtained:

$$
\Delta \mathrm{T}=\frac{\mathrm{T}_{0} \cdot \gamma}{\rho \cdot c_{v}} \cdot \Delta\left(\varepsilon_{x x}+\varepsilon_{y y}+\varepsilon_{z z}\right)
$$

where:

$\varepsilon_{\mathrm{xx}}, \varepsilon_{\mathrm{yy}}, \varepsilon_{\mathrm{zz}}:$ are the diagonal elements of strain tensor;

$\mathrm{c}_{\mathrm{v}}$ : thermal capacity at constant volume;

As described in equation (5) thermoelastic effect can be used as deformation analysis of any mechanical component appropriately loaded, manufactured in homogeneous, isotropic, linear elastic, material.

Thermoelastic technique can be useful to investigate both superficial stress and strain pattern: the first one in terms of the first invariant $\sigma$ I while the second in terms of hydrostatic invariant $\varepsilon \mathrm{I}$ of strain tensor $\varepsilon \mathrm{i}, \mathrm{j}$.

Digital image correlation measurement technique is performed by taking pictures of a random pattern of black dots in white background 
painted on a loaded specimen, in order to measure the deformation field on the specimen surface [2]. Pictures must be taken in undeformed and deformed configuration. So it is possible to calculate the first strain invariant $\varepsilon I$ as the sum of the elements laying on the main diagonal of the strain tensor: therefore results obtained with DIC and TSA can be directly compared. In the case analyzed using simultaneously these techniques there are some compromise to satisfy:

- a uniform IR surface emission is necessary for a correct TSA acquisition, while DIC needs a high brightness speckle pattern.

- DIC acquisition is performed using high resolution cameras (generally more than $4 \mathrm{Mpxl}$ ), while TSA acquisition uses small focal plane arrays (typical dimension are 320x256 pixels).

So focusing camera and a thermocamera on the same areas, the spatial resolution of the first one is many times larger. Using specific software (based on a lot of marker points on the two images as a reference) the analysis can be centered to the same area in the specimen both for DIC than TSA. Realizing a specific speckle pattern based on very small size of white spots, the emissivity of the surface can be considered as constant. At the same time this pattern is useful for digital image correlation.

\section{A TYPICAL TEST CASE}

As a typical example of material difficult to be analysed by thethermoelastic measurement technique, because of the difficult to obtain adiabatic conditions, it is chosen a rubber specimen whose dimensions are $20 \times 15 \times 15 \mathrm{~mm}$. This specimen is fixed in a test machine that will stress it with a compressive harmonic load, as shown in Figure 1:

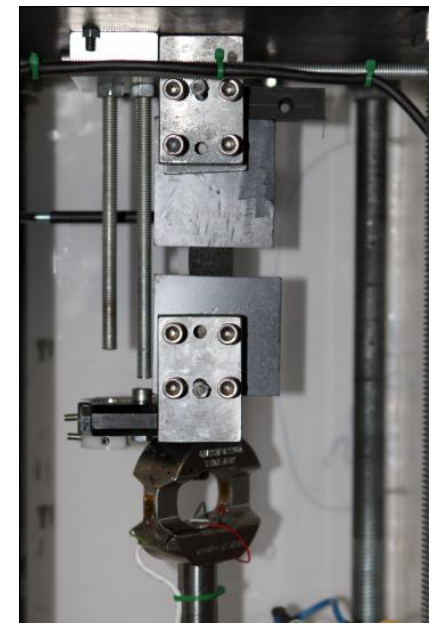

Fig. 1. Test Bench and rubber specimen.

Using a load cell and a potentiometer displacement transducer, the force applied and the global deformation of the specimen during testing are detected. The following table summarize the four peak to peak value levels of the force applied to the specimen and the relative displacements obtained.

Table 1. Test performed

\begin{tabular}{|c|c|c|}
\hline Test & Force $(\mathrm{N})$ & $\begin{array}{c}\text { Displacement } \\
(\mathrm{mm})\end{array}$ \\
\hline 1 & 200 & 0.8 \\
\hline 2 & 450 & 2.2 \\
\hline 3 & 600 & 2.4 \\
\hline 4 & 800 & 2.7 \\
\hline
\end{tabular}

Some preliminary analyses at different loading frequencies have been carried out to identify the optimal loading frequency that gives the best conditions of adiabaticity. For metallic materials this frequency is generally higher than $10 \mathrm{~Hz}$. Since the thermal conductivity of rubber is an order of magnitude lower than that of metals, it has been experimentally verified that a frequency higher of 2 $\mathrm{Hz}$ is sufficient. To perform the measurements by DIC technique in the specimen surface, a white speckle on the natural background (black) of the specimen is painted on sample surface. Since the extension of the white surface painted is less than $10 \%$ compared with the black background, no significant effects in the global thermal emission coefficient of the surface has been observed respect the unpainted surface, so the infrared thermography to measure surface temperature during the thermoelastic analysis can be used.

The thermoelastic system used for measurements is DeltaTherm 1550, manufactured by Stress Photonics, equipped with a thermocamera with a matrix of $320 \times 256$ sensors with a lens with $50 \mathrm{~mm}$ of focal length. The table 2 summarize the main technical characteristics of the measurement system.

Table 2. StressPhotonics DeltaTherm 1550 main characteristics.

\begin{tabular}{|c|l|}
\hline Frame Rate & $>1000 \mathrm{frame} / \mathrm{s}$ \\
\hline $\begin{array}{c}\text { Loading } \\
\text { Frequence Range }\end{array}$ & $0.6-1000 \mathrm{~Hz}$ \\
\hline Detector & $320 \times 256 \mathrm{InSb}$ \\
\hline $\begin{array}{c}\text { Thermal } \\
\text { Resolution }\end{array}$ & $2 \mathrm{mK}$ \\
\hline Band of sensivity & $3-5 \mu \mathrm{m}$ \\
\hline
\end{tabular}

When measurements on elastomeric materials are performed problems relating to poor achievement of adiabatic conditions come out, which are essential to make the thermoelastic analysis. For each test performed, at the different loading levels, specified in Table 1 , all at $2 \mathrm{~Hz}$, a thermographic film at 10 frames per second is acquired for a total time of $350 \mathrm{~s}$. At the same time photographic images have been acquired with a Canon EOS 7D camera equipped with a $24-70 \mathrm{~mm}$ lens.

The visible image acquisitions are synchronized with those of the thermocamera, resolution $5 \mathrm{mK}$. In Table 3 the optimal settings, experimentally obtained, of the digital camera are shown: 
Table 3. Parameters of visible image acquisition used

\begin{tabular}{|l|l|}
\hline Parameter & Value \\
\hline ISO & 320 \\
\hline Focal length & $70 \mathrm{~mm}$ \\
\hline Shutter speed & $1 / 25$ \\
\hline Array size & $3888 \times 2592$ pixel \\
\hline $\begin{array}{l}\text { Diaphragm } \\
\text { aperture }\end{array}$ & 16 \\
\hline
\end{tabular}

\section{THE MEASUREMENT RESULTS}

In the frames of the thermal films, a typical area of investigation of $25 \times 12$ pixel has been chosen. In Figure 2, on the left, this area is highlated and an enlargement of this, on the right, is shown.
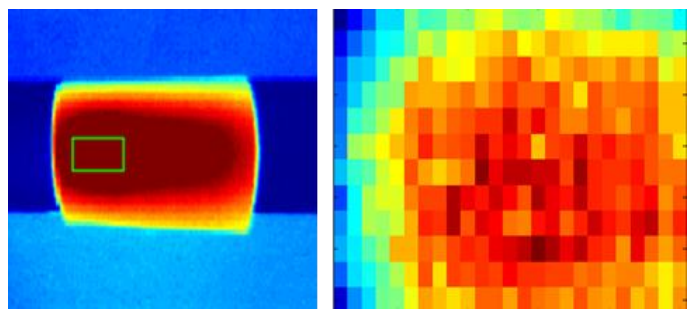

Fig. 2. Established area for the evaluation of the average temperature of reference (left) and enlargement of this area (right).

In this area average temperature has been calculated for each frame. The time evolution during the test of this average temperature is given in Figure 3:

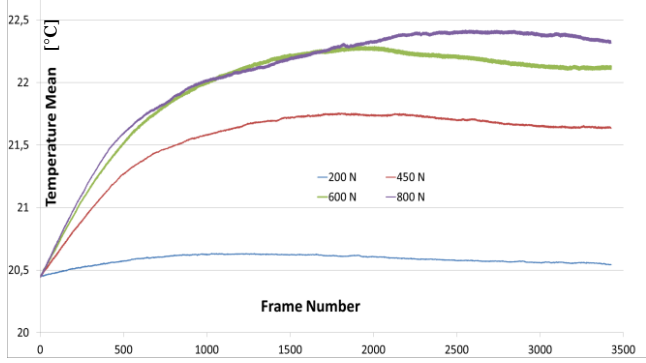

Fig. 3. Increasing of average temperature from test starting ad different loading levels.

It is generally known that the regime average temperature increases with the load level, showing an initial transient starting from room temperature. This transient is from 100 to 250 seconds. Only when the temperature remains constant the typical data processing of the thermal signal by lock-in technique in order to obtain differential thermograpy has been applied. The Table 4 below shows the selected frames of the thermal film analyzed after the initial transient. These frames are selected also because the Young's modulus remain constant, (it is well known that Young's modulus changes with the temperature).
Table 4. Selected frames for TSA analysis

\begin{tabular}{|c|c|c|}
\hline Loading level & Frame Range & $\begin{array}{c}\text { Average } \\
\text { Temperature }\left({ }^{\circ} \mathrm{C}\right)\end{array}$ \\
\hline $200 \mathrm{~N}$ & $1000-1500$ & 20.6 \\
\hline $450 \mathrm{~N}$ & $1800-2300$ & 21.7 \\
\hline $600 \mathrm{~N}$ & $2200-2700$ & 22.2 \\
\hline $800 \mathrm{~N}$ & $2500-3000$ & 22.4 \\
\hline
\end{tabular}

\section{THERMAL FILM ANALISYS}

The temperature fluctuation generated by the thermoelastic effect from equation (1) is extremely low. For this reason to detect its amplitude is commonly used the lock-in analysis technique.

It is possible to perform this analysis starting from the estimation of the Power Spectral Density (PSD) of time history of each pixel of the thermal film in order to identify the loading frequency from the highest peak of the PSD (Figure 4).

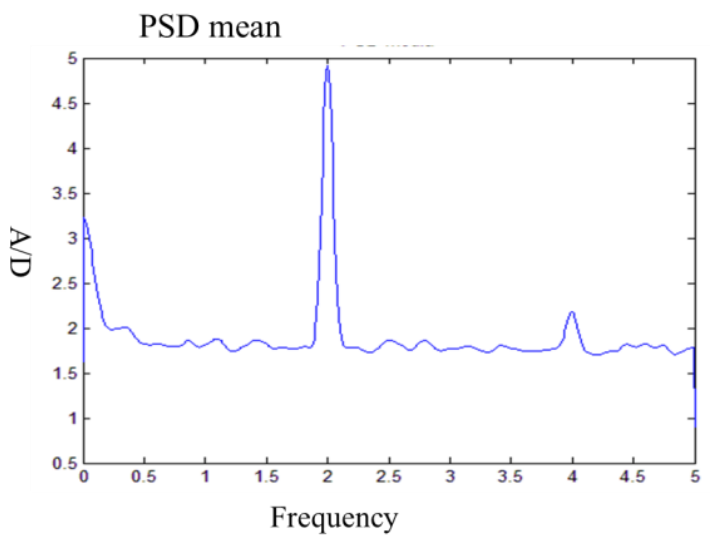

Fig. 4. Typical thermographic power spectral density calculated

To perform the lock-in data processing two square signals are generated at the frequency identified from the PSD and each square wave is multiplied by the time history signal of the pixel of the film and integrated to obtain real and imaginary part of the amplitude of fluctuation of the signal at this frequency.. The following figure shows a typical result of amplitude maps on specimen surface.

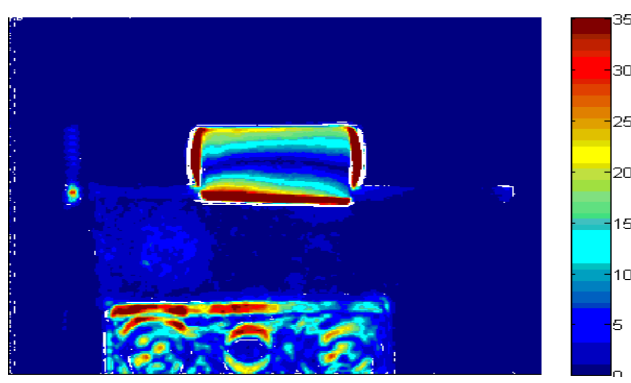

Fig. 5. Typical amplitude map from lock-in processing

In the following figures the results obtained at the four load levels studied are shown: 


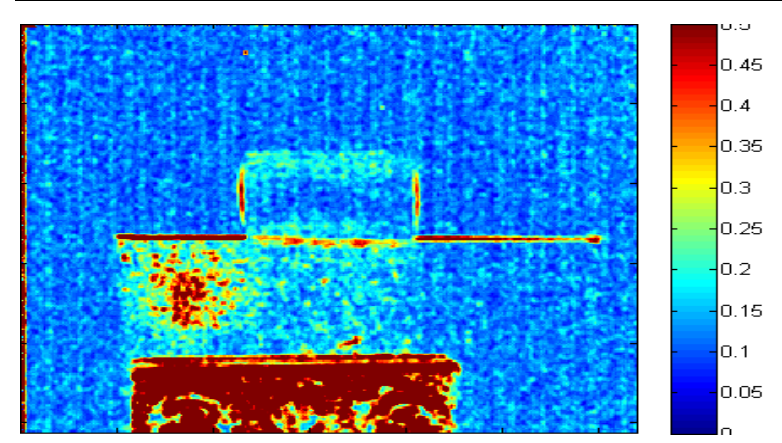

Fig. 6. Amplitude map distribution at $200 \mathrm{~N}$

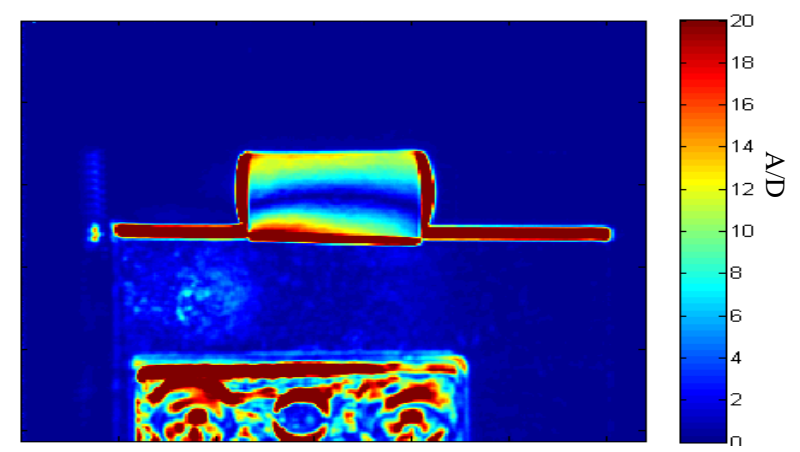

Fig.7. Amplitude map distribution at $450 \mathrm{~N}$

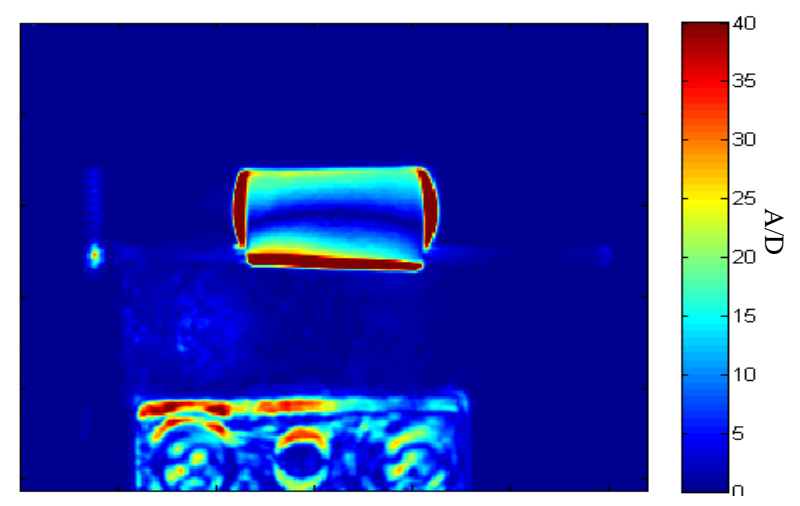

Fig. 8. Amplitude map distribution at $600 \mathrm{~N}$.

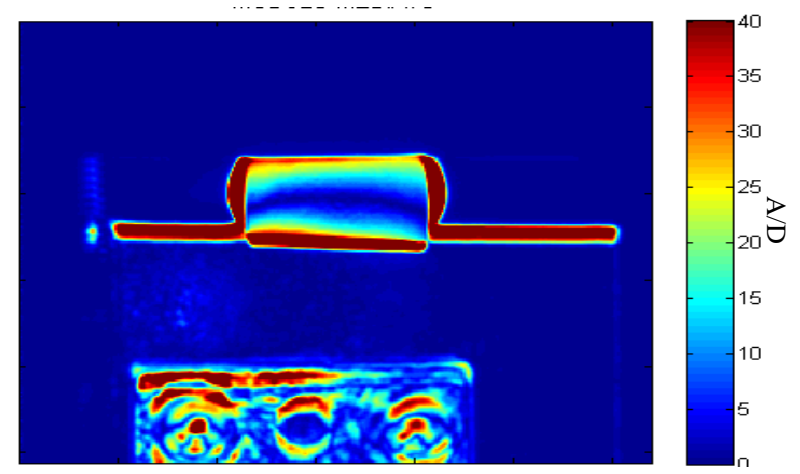

Fig. 9. Amplitude map distribution at $800 \mathrm{~N}$

Maps illustrated are proportional to the distribution of the first invariant of deformation on the surface of the specimen. The image in Figure 6 is less defined to the others do to the low signal to noise ratio because of the low level of loading. A typical result of analysis in the transient region at
$800 \mathrm{~N}$ loading is illustrated and it can be observed in Figure 10.

A high distortion can be observed due to nonadiabatic conditions.

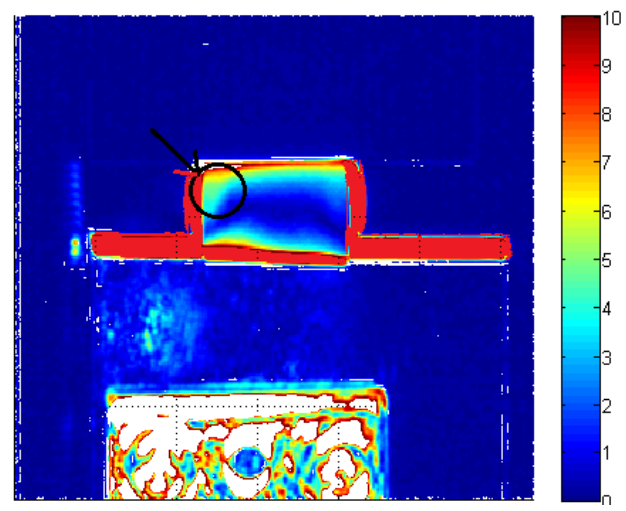

Fig.10. Typical example of thermoelastic analysis carried out in non-adiabatic conditions.

\section{DIGITAL IMAGE CORRELATION ANALISYS}

Digital Image Correlation data processing has been performed on a film recorded simultaneously to thermal film.

The images are acquired with a frame rate of 8 image/s and later processed with the Vic2d software by Limess. For each test vertical displacement and the first invariant of deformation are calculated. A typical example of results is shown in Figure 11.

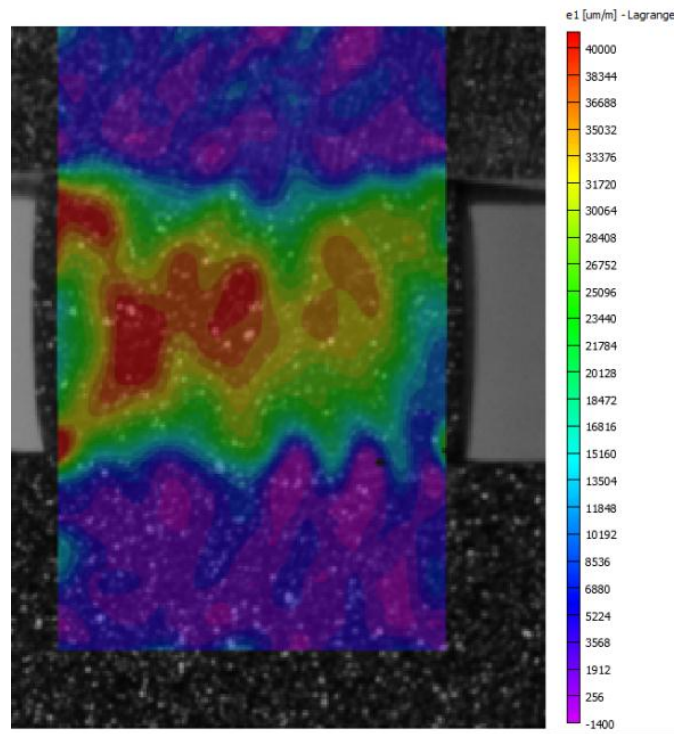

Fig. 11. Typical example of map of the first invariant of deformation in correspondence of the highest load applied

The analysis is carried out considering a subset of 50 pixels, a good compromise between spatial resolution and number of points to obtain a correct correlation. A typical trend of vertical displacement is given in Figure 12. 


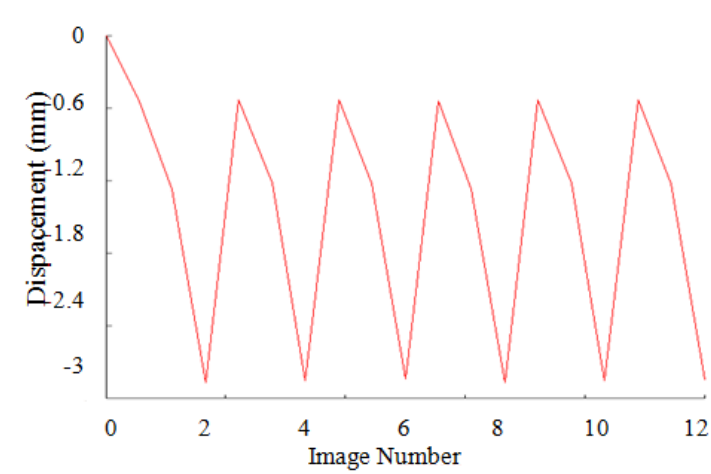

Fig. 12. Typical trend of vertical displacement obtained by DIC analysis in function of the acquired images.

This result agrees with global sample displacement measured by the reference potentiometer installed on the test bench.

\section{COMPARISON BETWEEN DIC AND TSA}

Comparison has been performed between the results of the first invariant of deformation measured by thermoelastic technique and the same obtained by DIC technique.

A specific software has been developed in order to interpolated results on same specimen surface with same resolution. Ratio between thermoelastic maps and DIC maps are calculated for each test performed and it is show in the following figures.

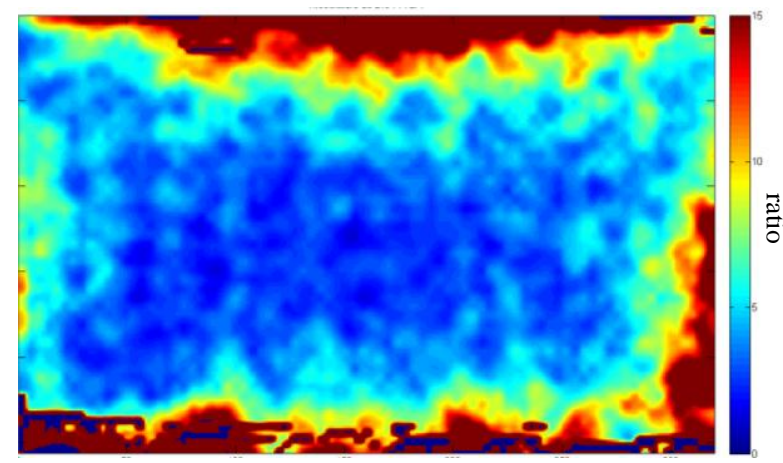

Fig. 13. Ratio between first stress invariant TSA/DIC at $200 \mathrm{~N}$.

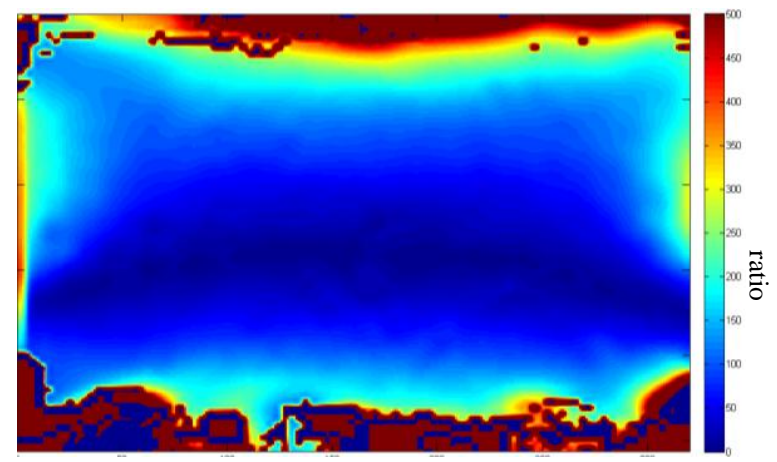

Fig. 14. Ratio between first stress invariant TSA/DIC at $450 \mathrm{~N}$.

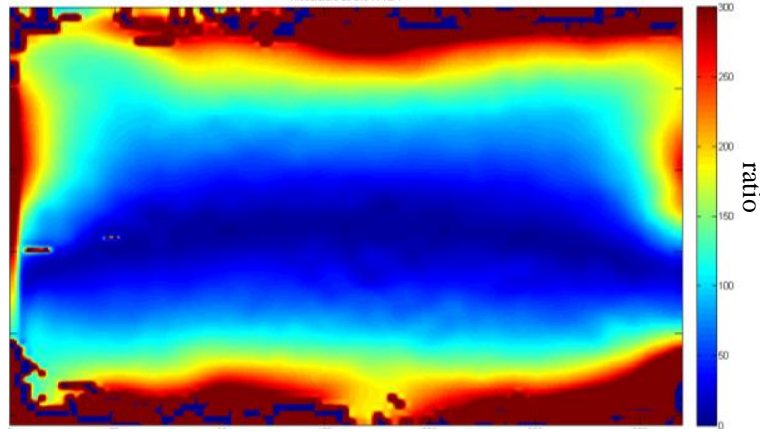

Fig. 15. Ratio between first stress invariant TSA/DIC at $600 \mathrm{~N}$.

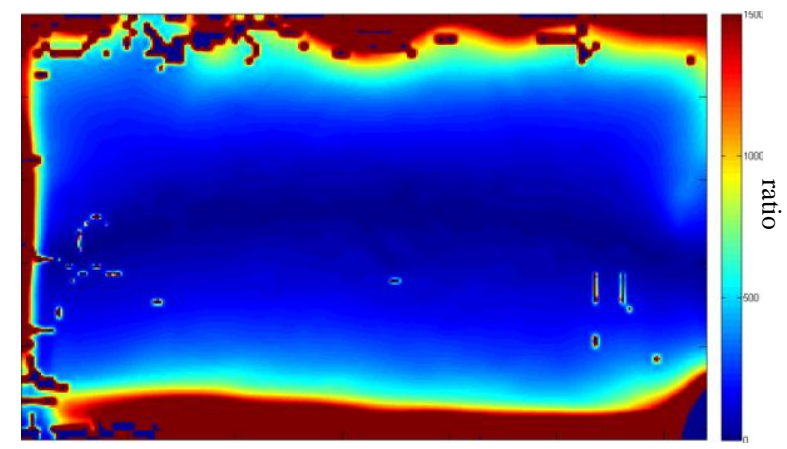

Fig. 16. Ratio between first stress invariant TSA/DIC at $800 \mathrm{~N}$.

The ratio obtained is not constant in specimen surface and it is different in the four images. Differences are mainly due to spatial changes of thermoelastic coefficient, also due to temperature spatial distribution on specimen surface. It is therefore defined a constant $\mathrm{k}$ as:

$$
k=\frac{\overline{T S A}}{\overline{E_{1}}}
$$

Where:

$E_{1}$ : average value of the first deformation invariant calculated with DIC technique in a specific investigation area.

TSA: average value of the first invariant of deformation calculated with TSA technique in the same investigation area.

The following illustration shows an example of results of the first invariant of deformation obtained with the two methodologies. The square highlights the investigation area, with low gradient of deformation, used to calculate the $\mathrm{k}$ coefficient.

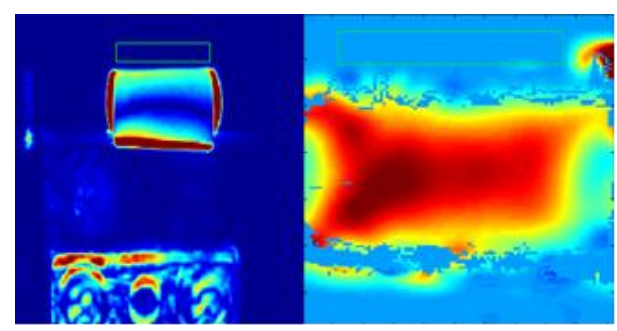

Fig. 17. Typical example of results with TSA technique (left) and DIC (right), where the area identified to calculate $\mathrm{k}$ is highlighted. 
Using the parameter $\mathrm{k}$, maps are rescaled by $\mathrm{k}$, obtaining results of Figure 18 to 21.
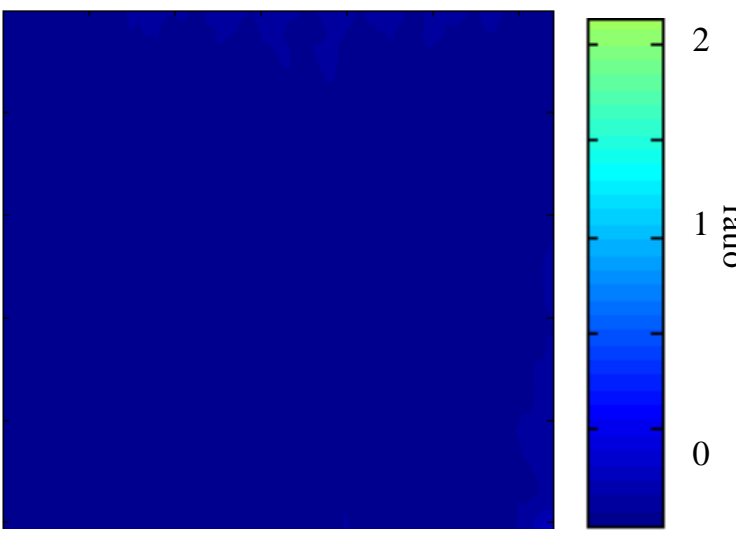

Fig. 18. Rescaling at $200 \mathrm{~N}$
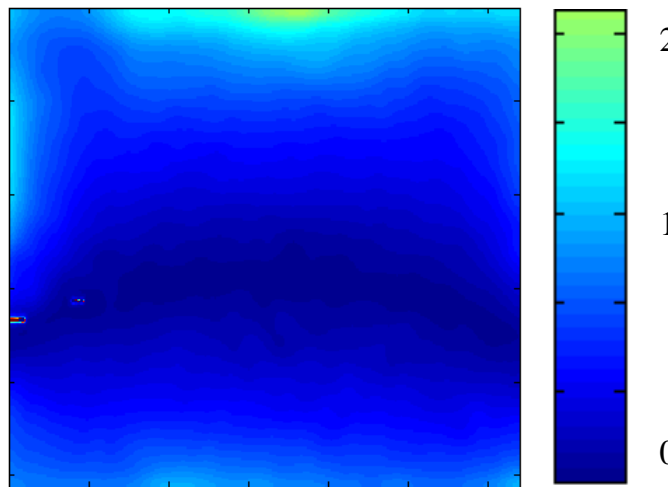

Fig. 19. Rescaling at $450 \mathrm{~N}$
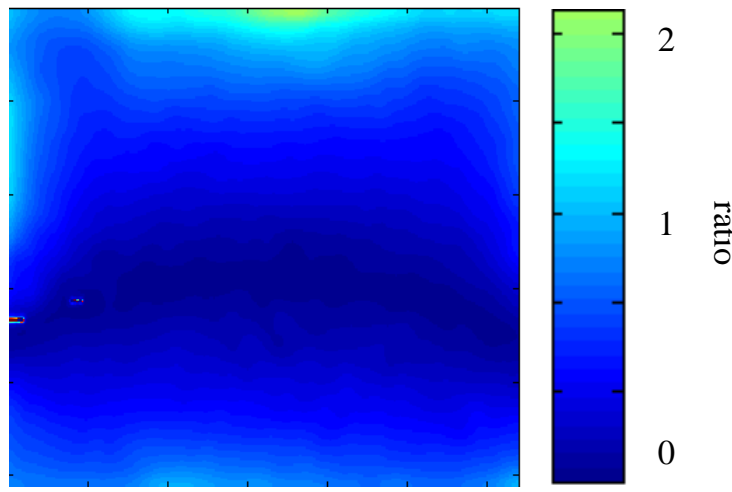

Fig. 20. Rescaling at $600 \mathrm{~N}$.
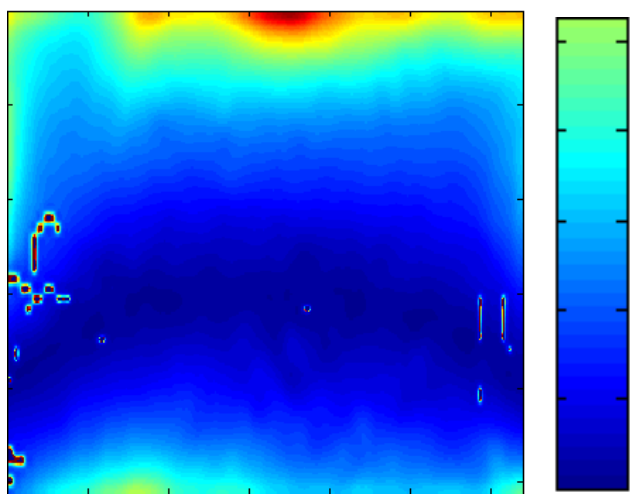

From images it can be seen that the new ratio calculated remains almost constant, with a difference below $5 \%$. The worst results are obtained in the case of a load of $200 \mathrm{~N}$ due the modest signal to noise ratio because of the low loading of the sample.

\section{CONCLUSION}

For dynamic materials characterisation it is possible to use, in a simultaneous way, two noncontact full field measurement techniques based on data processing of a video and a thermal film both allow to measure the distribution on the component's surface of the first invariant of deformation $\varepsilon_{\mathrm{I}}$. Comparison between the two techniques allow to better identify their performances and limitation and allow to calculate correct value of thermoelastic constant, related to material parameters in the testing condition. The combination of the two measurement techniques do not need other reference techniques for data scaling in stress-strain units.

The ratio $k$ calculated remains almost constant, with a difference below $5 \%$.

\section{REFERENCES}

1. Thomson W. On the thermoelastic, thermomagnetic and pyro-electric properties of Matter, Phil. Mag., 1979; 5:4-27.

2. Chu TC, Ranson WF, Sutton MA, Peters WH. Application of digital image correlation techniques to experimental mechanics. Experimental Mechanics, 1985; 25 : 232-244.

3. Harwood N, Cummings WM, Mackenzie AK. An introduction to thermoelastic stress analysis, Ed Adam Hilgher, 1991.

4. Belgen MH. Structural Stress Measurements with an Infrared Radiometer, ISA, Trans., 1967; 6.

5. Barone, Patterson. Full field separation of principal stresses by combined thermo and photoelasticity, Experimental Mechanics, 1986; 36( 4):318-32.

6. Sakagami, Kubo, Fujinami, Kojima, Applications of experimental stress separation technique using thermoelasticity and photoelasticity to fracture mechanics, Int conf. ATEM'03, JSME-MMD, September 10-12, 2003.

7. Sutton MA, McNeil SR, Jang J, Babai M.Effect of subpixel image restoration on digital correlation error estimates, Optical Enginering. 1988; 27: 870-877.

8. Sakagami, Kubo, Kojima. J-Integral Evaluation based on experimentally stress separation measurement by thermoelasticity and photoelasticity, ICEM12-12th International Conference on Experimental Mechanics, Politecnico di Bari, 29 August-2 September, 2004.

9. Weber W. Uber die specifische Warme fester Korperinsbesondere der Metalle, Ann d. Physik u. Chemie, 1830; 96: 177-213.

10. Becchetti, M, Flori, R, Marsili, R, Rossi G. Stress and strain measurements by image correlation and thermoelasticity. Society for Experimental Mechanics - SEM Annual Conference and Exposition on Experimental and Applied Mechanics 2009;1:70-75. 
11. Garinei A, Marsili R. Development of a new capacitive matrix for a steering wheel's pressure distribution measurement. International Journal of Industrial Ergonomics, 2014; 44(1): 114-119. http://dx.doi.org/10.1016/j.ergon.2013.11.012.

12. Brustenga G, Marsili R, Moretti M, Pirisinu J, Rossi G. Measurement on rotating mechanical component by thermoelasticity. Journal Applied Mechanics and Materials, 2005; 3-4: 337-342.

13. Garinei A, Marsili R. Design of an optical measurement system for dynamic testing of electrospindles", Measurement, 2013; 46(5): 17151721. http://dx.doi.org/DOI:10.1016/j.measurement.2013.01.006.

14. Cardelli E, Faba A, Marsili R, Rossi G, Tomassini R. Magnetic nondestructive testing of rotor blade tips, Journal of Applied Physics, 2015; 117:17A705 http://dx.doi.org/10.1063/1.4907180.

15. Garinei A, Marsili R. Thermoelastic Stress Analysis of the Contact Between a Flat Plate and a Cylinder, Measurement: Journal of the International Measurement Confederation, 2014; 52 (1): 102-110 http://dx.doi.org/10.1016/j.measurement.2014.03.005

16. Brouckaert JF, Marsili R, Rossi G. Development and experimental characterization of a new non contact sensor, 10th International Conference on Vibration Measurements by Laser and Noncontact Techniques AIVELA, Ancona, ItalyAIP Conference Proceedings, 2012, $\quad 1457: \quad 61 \quad-68$ http://dx.doi.org/10.1063/1.4730543.

17. Garinei A, Marsili R. A new diagnostic technique for ball screw actuators, Measrement, 2012; 45(5): 819828. http://dx.doi.org/10.1016/i.measurement.2012.02.23.

18. D'Emilia G, Lucci S, Natale E, Pizzicannella F. Validation of a Method for Composition Measurement of a Non-Standard Liquid Fuel for Emission Factor Evaluation, Measurement, 2011; 44: 18-23.

19. D’Emilia G, Razzè L, Zappa E. Uncertainty Evaluation of High Frequency Image-Based Vibration Measurement, Measurement, 2013; 46(8): 2630-2637.

20. D’Emilia G, Di Rosso G, Gaspari A, Massimo A. Metrological interpretation of a six sigma action for improving on line optical measurement of turbocharger dimensions in the automotive industry, Proceedings of the Institution of Mechanical Engineering: Part D, Journal of Automobile Engineering, 2015;229(2): 261-269. http://dx.doi.org/10.1177/0954407014539671.

21. D'Aponte F, D'Emilia G, Lupinetti S, Natale E, Pasqualoni P. Uncertainty of slip measurements in a cutting system of converting machinery for diapers production. Int. J. Metrol. Qual. Eng., 2015;6(3):1-6.

22. Speranzini E, Agnetti S, Corradi M. Experimental analysis of adhesion phenomena in fibre-reinforced glass structures", Composites part B, 2016; 101:155166.

http://dx.doi.org/10.1016/j.compositesb.2016.06.074.

23. Speranzini E, Tralascia S. Engineered Lumber: LVL and Solid Wood Reinforced with Natural Fibres. In Proceedings of the WCTE 2010-Word Conference on Timber Engineering, Trento, Italy, 20-24 June 2010: 1685-1690.

24. Speranzini E, Agnetti S. Structural performance of natural fibers reinforced timber beams. In Proceedings of the 6th International Conference on
FRP Composites in Civil Engineering-CICE2012, Roma, Italy, 13-15 June 2012.

25. Corradi M, Borri A, Castori G, Speranzini E. Fully reversible reinforcement of softwood beams with unbounded composite plates. Composite Structures, 2016:149:54-68. http://dx.doi.org10.1016/j.compstruct.2016.04.014.

26. Becchetti M, Flori R, Marsili R, Moretti M. Comparison between digital image correlation and thermoelasticity for strain field analysis, 9th International Conference on Vibration Measurements by Laser and Noncontact Techniques and Short Course; Ancona; Italy; AIP Conference Proceedings, 2010;1253: 233-240. http://dx.doi.org/10.1063/1.3455462.

27. Marsili R, Moretti M, Rossi G. Thermoelastic Modal Stress Analysis, IMAC XXVI Conference \& Exposition on Structural Dynamic, Orlando, Florida USA, 4 - 7 February, 2008.

28. Speranzini E, Marsili R, Moretti M, Rossi G. Image analysis technique for material behavior evaluation in civil structures. Materials, 2017;10(7): 770. http://dx.doi.org/10.3390/ma10070770.

Received 2017-09-15

Accepted 2017-11-28

Available online 2017-12-18

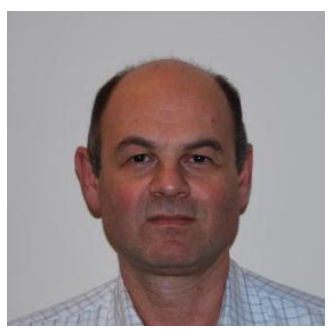

Roberto MARSILI is Researcher of Mechanical Measurements at University of Perugia. He is graduated in Mechanical Engineering and he obtained the $\mathrm{PhD}$ degree from University of Padova studying piezoelectric films. His area of interest regards diagnostics of mechanical systems, thermoelastic stress analysis.

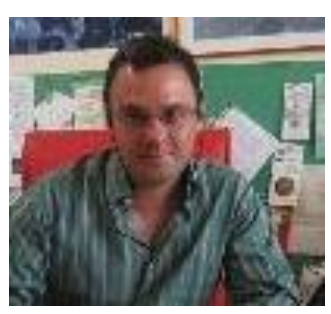

Gianluca ROSSI is full Professor of Measurement and Testing at Dep.t of Engineering University of Perugia Since June 2014, President of Non-profit Association TUCEP - Tiber Umbria Comett Education Programme, European research centre and training provider. The main activities and responsibilities are: research group management; teaching in Mechanical Engineering and Measurement Science courses; teaching non contact measurement techniques of stress and strain by digital image correlation and thermoelasticity, thermography, fluid field analysis. 